\title{
Conflict Rate and Job Satisfaction among Staffs in the Islamic Republic of Iran: Rafsanjan Township as a Case Study
}

\author{
Mohammad Naji \\ Faculty of Human Ecology, Payame Noor University \\ Payame Noor University, Anar, Kerman, Islamic Republic of Iran \\ E-mail: mohammadnaji1356@gmail.com \\ Hamied Tabouli, Phd \\ Head of Payame Noor University of Kerman \\ Islamic Republic of Iran
}

Received: October 30, 2010 Accepted: December 20, $2010 \quad$ doi:10.5539/ach.v3n2p49

\begin{abstract}
This study is to investigate conflict rate and job satisfaction among staffs in the public organizations in Rafsanjan Township in the Islamic republic of Iran. In this study, staffs personality, laws and guide directions, staffs needs, communications and job satisfaction is investigated by examining the staffs' salary, job nature, supervisor and salary of staffs' colleagues and their promotion. This was a quantitative study. All data of this study have been collected by using questioner. All data of this study have been analyzed quantitatively by using the SPSS software. Statistical society of the study was people who have worked in the public organizations in Rafsanjan Township. This study has chosen 385 staffs and has distributed two types of questionnaires namely job satisfaction and conflict questioners among them randomly. Finally, this study has concluded that
\end{abstract}

1. There is a reciprocal relationship between conflict rate and job satisfaction.

2. There is a negative relationship between conflict rate and payments.

3. There is a reciprocal relationship between conflict rate and job nature.

4. There is a negative relationship between conflict rate and supervision style.

5. There is a negative relationship between conflict rate and colleagues.

6. There is a reciprocal relationship between conflict rate and promotion opportunity.

Keywords: Job satisfaction, Conflict, Perception and organization

\section{Introduction}

Conflict is a very important concept, because, researches have shown that top and mid managers spend their main time to solve the problem. Conflict maybe is a result of contradictory requests among a group and maybe is a result of different definitions from a person's job and responsibilities. Conflict is a behavior that happens among members of an organization in order to disagree with others. It happens whenever they have an incongruous with others. Overall, intense and high level of conflict reduces the effect of organization behaviors and job satisfaction. On the contrary, low and mild level of conflict reduce stagnate and increase initiative and innovation. In any way, job satisfaction consist perception of a person toward his/her job. As mentioned high level of conflict reduces the job satisfaction and a mid level of conflict increases the job satisfaction. Therefore, there is a bilateral relationship between job satisfaction and level of conflict. A mid level of conflict is very suitable to improve the organizational behaviors. This fact is clear that there is a conflict in organizations and it can affect on the organizational behaviors. Therefore, managers should try to manage this conflict in a suitable way in order to improve the organizational functions. Conflict would be formulated by some incompatible behaviors. This process deals with two sides: A person opposite to another person to hold back him/her in his/her job(Robbins, 2004). In conflict, goals and behaviors of a person or group can be blocked by a person or a 
group(Ghasemi, 2003, p. 379). It is very necessary to notify that conflict always is not harmful. It has two dimensions: creative and uncreative.

1. Creative conflict strengthens goals of a group and organizational behaviors.

2. Uncreative conflict discourages goals of a group and organizational behaviors(Haghighi, Borhani, Mashof, \& Korderostami, 2005, p. 355).

Conflicts have also different degrees from intense to mild.

1. Altercation: in this process, two or several persons argue with together regarding a special matter

2. Competition: in this process, two or several persons try to achieve a same goal.

3. Opposition: in this process, two or several persons opposite to other in achieving their goals.

4. Dispute: dispute is a kind of negative competition along with harshness(Ghasemi, 2003, p. 382). In this process, two or several persons try to achieve their goals by annihilating others.

Conflict is interconnected with an organization and social life. That means that it is like whether for human which cannot be separated from an origination. Therefore, an origination should live with conflict (Najafbeygi, 2000, p. 129).

Job satisfaction is a variable that has been affected by conflict. Job satisfaction shows the view of people toward a job and an organization. Job unsatisfaction increases the protest, objection, complaint, remonstrance, contradiction, disapproval and expostulation. Thus, the importance of conflict is very clear for everybody to be investigated in a social life and an organization. Recognition of conflict and its dimensions improve and guide an organization in achieving to its goals. This is, because high and intense conflict severely and negatively influence on the functions of an organization. Unlike low and mild conflict weakly and positively influence on the effects of an organization.

Conflict influence on both job satisfaction and job unsatisfaction. As it mentioned earlier, Job unsatisfaction increases the protest, objection, complaint, remonstrance, contradiction, disapproval and expostulation(Asghari, 2007, p. 74). Job satisfaction is a kind of people positive conception toward their job and its dimensions including payment, job nature, promotion opportunities, supervisor and colleagues.

\section{Methodology}

The topic of this study is to investigate the conflict rate and job satisfaction among staffs in public organizations in the Islamic republic of Iran: Rafsanjan Township as a case study. This study has used a collective descriptive method to achieve the goals of the study. This study has used the method, because, this method describe every phenomenon under the study exactly and completely(Bast, 2002, p. 142).

\subsection{Statistical Society}

Statistical society of the study consists of all staffs that had worked in the governmental organizations in the Rafsanjan Township, Kerman state, Islamic Republic of Iran. They were 6 thousands and 336 people.

\subsection{Sampling Methods}

Stratified random sampling method has been used, because, different number of people in organizations are worked. Staffs should be involved according to their number in the statistical society. 385 staffs have been involved in this study. They have been chosen among 6 thousands and 336 people randomly.

\subsection{Data Collection Methods}

This study has used a questioner to collect the needed data. This study has designed two questioners for collecting two kinds of data: conflict rate data and job satisfaction data. Questioner regard to conflict rate has 30 questions and questioner regarding to job satisfaction among staffs has 20 questions.

\subsection{Data Analysis Methods}

The software named SPSS are used to analysis the data of this study. In addition to that, qualitative statistics including tables, figures, averages and statistical tests including Spearman and Kendal's collective tests have also been used to analysis the data.

\subsection{Indicators Description}

In this step, statistical indicators taken by sampling have been designed in form of figures. The results of these indicators have also been evaluated according to the variables. (Refer to Figure 1, 2 and 3). 


\section{Results}

This study has shown that there is a meaningful connection between organizational conflict rate and job satisfaction of staffs. According to $-\mathrm{P}$, the rate of independence test which is equal to $0 / 000$, hypostasis 0 is rejected. That means that two variables of conflict rate and job satisfaction are not independence. There is a meaningful connection among them. To investigate this connection, collective test is used. Based on the Spearman (-0 /407) and Kendal's (-0/359) collective coefficients, meaning of both of two tests is equal to 0/00. Therefore, hypostasis 0 is rejected, because, both of $-\mathrm{P}$ are less than meaning level $(0 / 05)$. As a result, there is a connection between organizational conflict rate and job satisfaction. In addition to that, negative collective coefficient is shown that there is a contrary connection among these two variables. (Refer to Figure 4)

\section{Discussion}

Researches that have been conducted by some researchers have shown that extensive conflict reduces effectiveness and job satisfaction. This conflict level also increases the absence rate and staffs offset. Overall, it is necessary to note that existence of conflict is not unsuitable for organizations rather it is very useful and suitable for improving the effectiveness of organizations. It can also be concluded that job background and sex variables are separated from organizational conflict and job satisfaction. They don't interfere in conflict and satisfaction. As a conclusion, managers have not to spend their time for these two variables. Instead, age and education have a meaningful relationship with organizational conflict and job satisfaction. That means that increase of the organizational conflict reduce job satisfaction(Ahamadvand, 2007; Haghighi et al., 2005). Therefore, mangers have to pay attention on these two variables in improving their effectiveness.

\section{Conclusion}

Finally, this study have concluded that

1. H0: This study finally has concluded that there is no any connection between organizational conflict and job satisfaction.

2. H1: there is a good connection between organizational conflict and job satisfaction.

According to Spearman and Kendal's collective tests, there is a bilateral relationship between organizational conflicts.

\section{Recommendations}

Finally, this study would like to make some recommendations for future studies. If the researchers want to do same study in the future, the following recommendations should be met. This is, because the researcher firmly understood that these recommendations will help to generate better results.

1. Mangers should use organizational conflict for improving their effectiveness.

2. Managers should provide a circumstance for positive using form organizational conflict

3. Managers should pay attention to staffs' job for creating a job satisfaction

4. Mangers should pay attention to staffs' salary along with their work

5. Managers should pay attention to all his/her human capital

6. Managers should prepare a suitable space for job promotion among his/her staffs

7. Managers should pay attention to job relations for maximizing the job satisfaction

8. Mangers should pay attention to the job diversities

9. Mangers should attempt for creating a suitable job space

10. Mangers should good look to organizational regulation and rules

11. Mangers should try to increase the physical and mental health among their staffs

12. Managers should attempt to reduce stress in work space

13. Managers should attempt to create a competition space in their organization

14. Mangers should attempt to create a positive motivation among their staffs

15. Managers should try to create a seeking and creative space in order to improve the organizational effectiveness.

16. Based on the research, this study recommends that some researchers do same studies in others township in Kerman state and compare the results. 


\section{References}

Ahamadvand, M. A. (2007). Mental Health (Vol. 14). Tehran: Payame Noor University.

Asghari, J. (2007). Organizational Behaviors Management (Vol. 1). Tehran: Safa.

Bast, J. (2002). Behaviors and Organizational Cultural Science, In h. Sharifipasha \& N. Taleghani (Eds.), (Vol. 9). Tehran: Roshd.

Ghasemi, B. (2003). Organizational Behaviors Management. Tehran: Termeh.

Haghighi, M., Borhani, B., Mashof, S., \& Korderostami, M. (2005). Organizational Behaviors Management. Tehran: Termeh.

Najafbeygi, R. (2000). Organization and Management (Vol. 1). Tehran: Open University of Iran.

Robbins, S. P. (2004). Organization Theory: Structures, Designs, And Applications, 3/e. Pearson Education India.

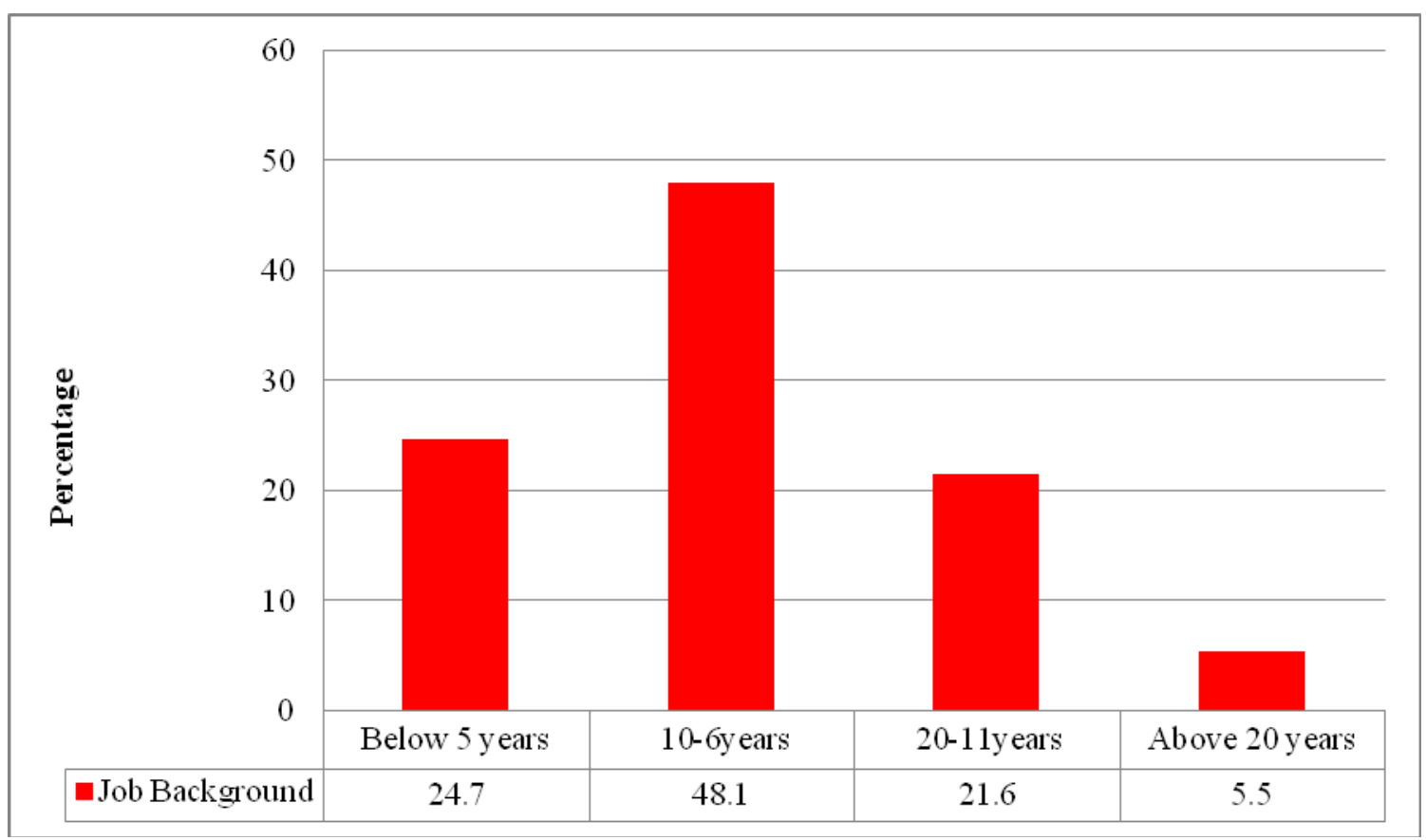

Figure 1. Job Background of the Respondents 


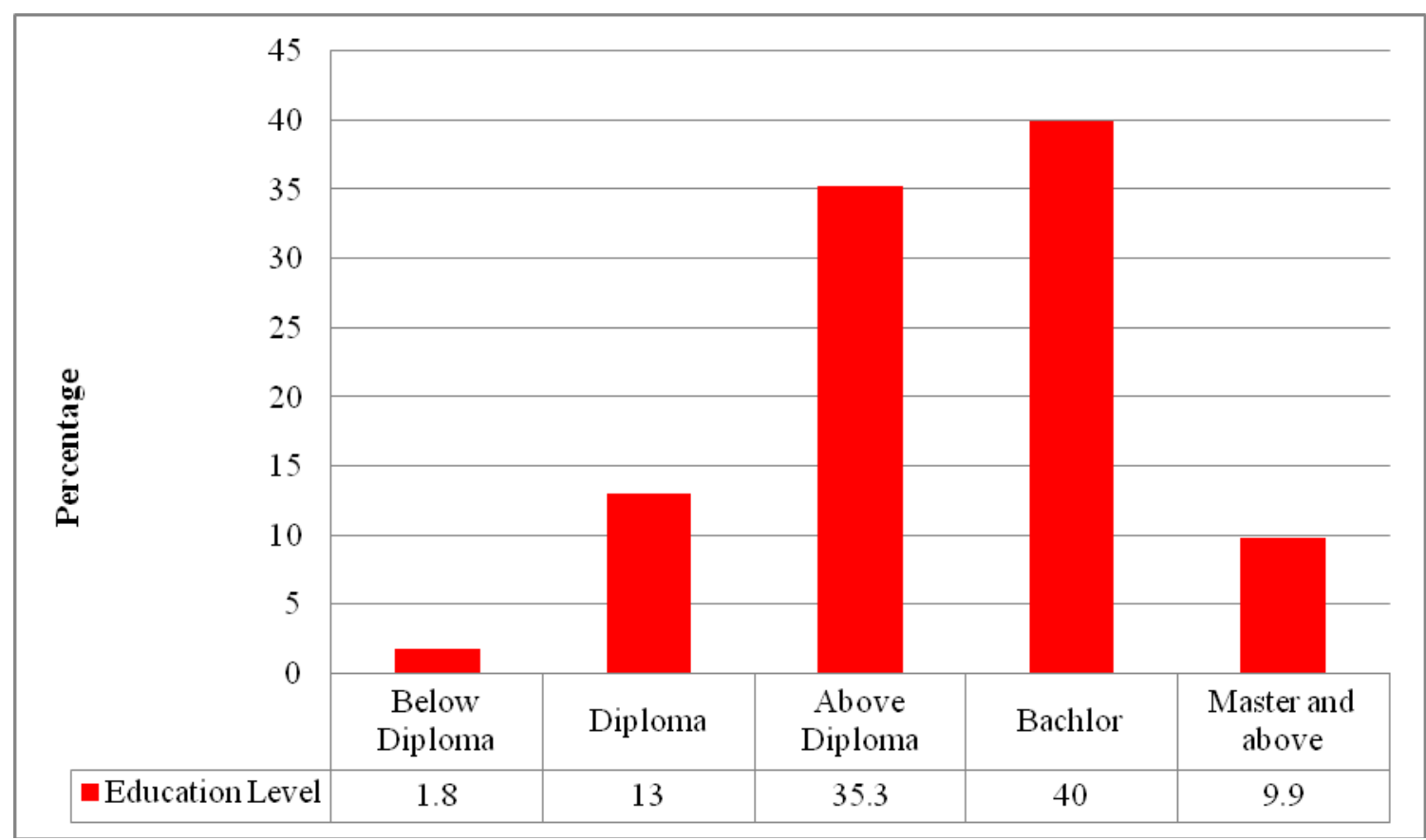

Figure 2. Education Level of Respondents

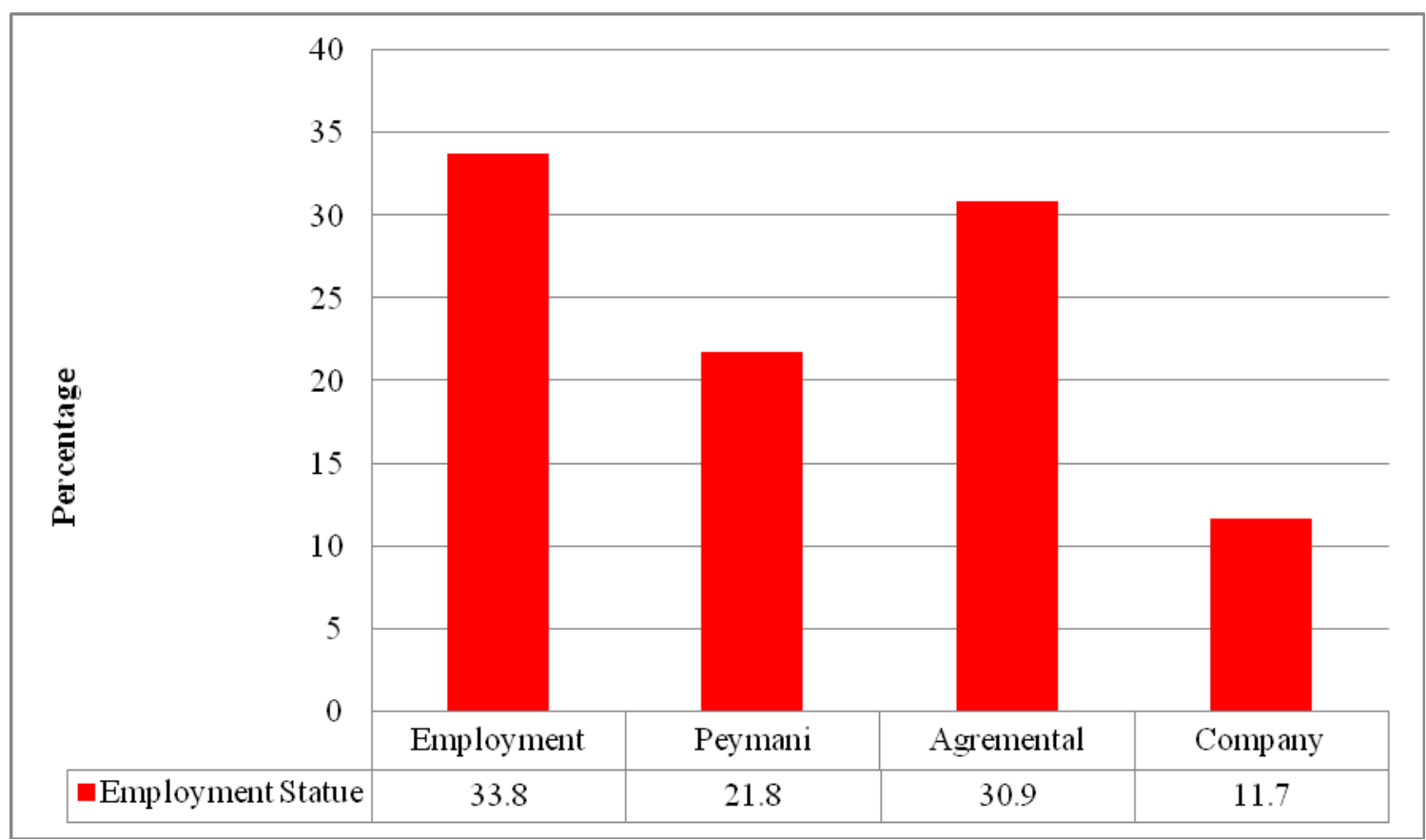

Figure 3. Employment Statue of Respondents 


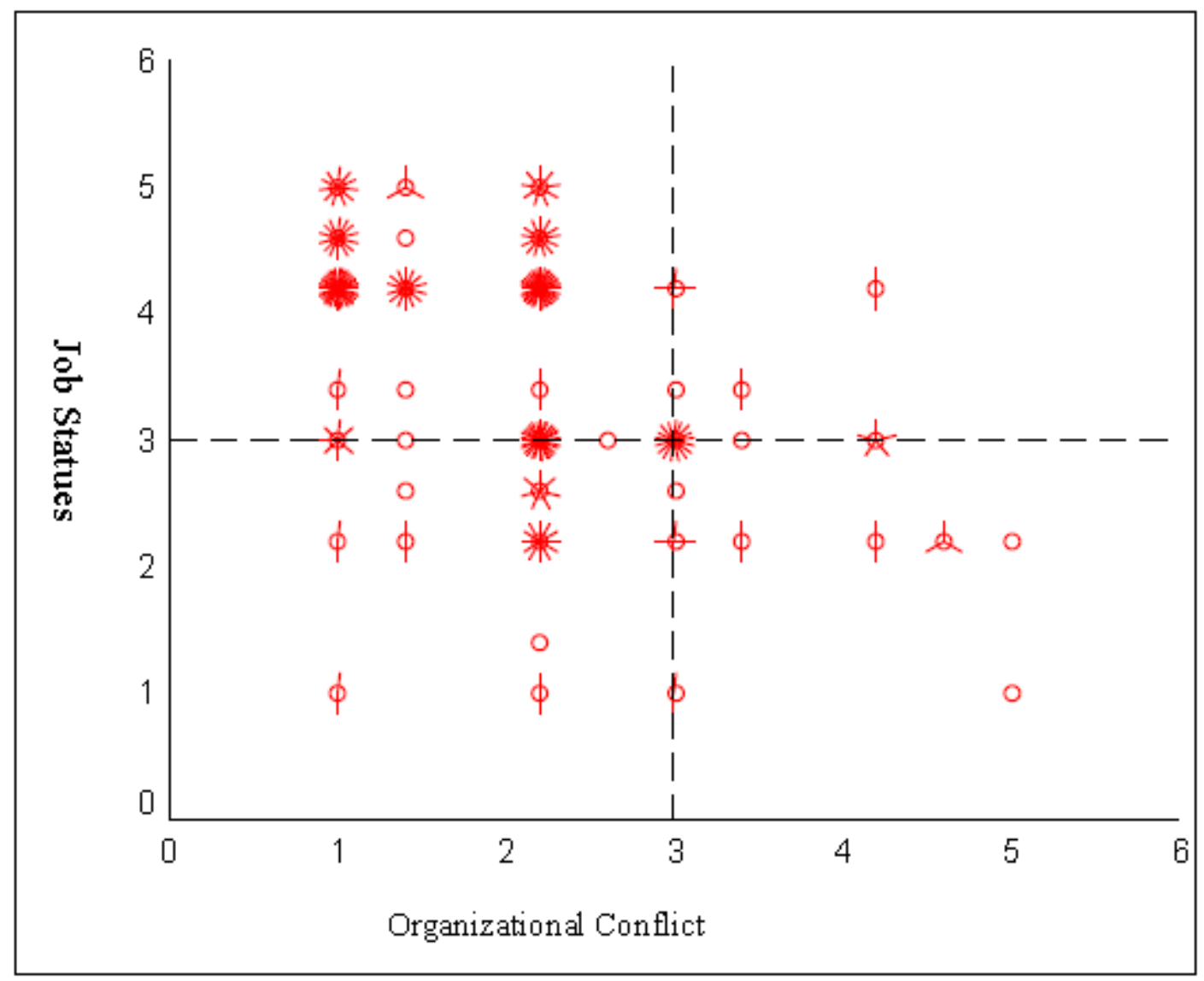

Figure 4. Organizational Conflict Comparing to Job Satisfaction 